\title{
AOR
}

Selected Papers of \#AolR2020:

The $21^{\text {st }}$ Annual Conference of the

Association of Internet Researchers

Virtual Event / 27-31 October 2020

\section{IT'S REWIND TIME, EVERYBODY: THE CONTESTATION OF PLATFORM CULTURE IN YOUTUBE'S YEARLY REVIEW}

\author{
CJ Reynolds \\ The Hebrew University of Jerusalem
}

YouTube Rewind, especially its controversial 2018 and 2019 offerings, surfaces contested and contradictory understandings of what YouTube culture is and who gets to speak for the platform. In 2018, YouTube's blog excitedly announced the release of annual year-in-review video, YouTube Rewind. Titled "Everyone Controls Rewind," the video highlighted the ostensible control YouTube gives creators over their content, audiences, and platform culture. Tellingly, however, the first paragraph of the blog post mentions only celebrities with limited presence on the platform like Kylie Jenner, Will Smith, and Beyoncé. It was perhaps predictable, then, that many YouTube viewers swarmed to the video only to feel ostracized and powerless watching mainstream celebrities and scripted skits that gave homage to corporate visions of the platform rather than viral and unique moments. Rewind videos have traditionally featured stars whose fame is closely tied to the platform, like PewDiePie, Smosh, and Logan Paul, or memes that rose to prominence via YouTube like Psy's "Gangnam Style" or Rebecca Black's "Friday." In 2018, however, many of YouTube's most notable faces were conspicuously absent and the memes and culture they represented only minimally acknowledged.

In an effort to take back control, viewers struck at YouTube in one of the few ways readily available - the dislike button. Within days, Rewind 2018 surpassed one of YouTube's most ignominious records, becoming the most disliked video of all time with over sixteen million people clicking the thumbs down button. Where the previous recordholder, Justin Bieber's "Baby," took almost ten years to acquire ten million dislikes, YouTube Rewind reached the mark in eight days. The backlash was severe enough that YouTube executives considered removing the dislike button across the entire platform (Palladino 2019) and YouTube CEO Susan Wojcicki's own children informed her that the video was "cringey," eventually prompting the company to publicly acknowledge its mistake. "We hear you," Wojcicki wrote in a blog post, admitting that

Suggested Citation (APA): Reynolds, C. (2020, October). It's rewind time, everybody: The contestation of platform culture in YouTube's yearly review. Paper presented at AoIR 2020: The $21^{\text {th }}$ Annual Conference of the Association of Internet Researchers. Virtual Event: AolR. Retrieved from http://spir.aoir.org. 
Rewind 2018 "didn't accurately show the year's key moments, nor did it reflect the YouTube you know" (Wojcicki 2019).

YouTube Rewinds serve as occasions of "festive viewing" driven, in this case, by an online video platform rather than a traditional television broadcaster (Dayan and Katz 1992, 1). Adopting and adapting the idea of media events established by Dayan and Katz to fit the change in medium, I argue that Rewinds serve as social media events. Like media events on television, Rewinds interrupt the everyday business of YouTube. They are a dominant moment of shared culture on a platform saturated with more content than the entire history of broadcast television at over 500 hours of video added per minute (Wojcicki 2020). Rewind 2018 alone boasts over 170 million views and thousands of response videos. Rewinds are annual, preplanned, and heavily advertised, with release dates announced on social media up to a week before the video's debut, factors that build a sense of ceremony around jointly celebrating a year in YouTube culture. These are moments of coming together with shared rituals (Burgess, Mitchell, and Münch 2018, 10), anthems, and cultural leaders. And, most tellingly, violating the formula for this ceremonial event upset audiences to the point of generating a mass, organized, and negative response.

By focusing on the question of cultural development on YouTube through the social media event of Rewind videos, I aim to develop the larger question of how researchers can talk about online culture on a globalized scale. YouTube's 2019 version of Rewind, "For the Record," offers one strategy for how to do this. In the wake of missing the cultural tone of the platform in 2018, YouTube retreated to metrics as a way to understand it in 2019. "For the Record" returned to the strategy of the first Rewind in 2010 of simply counting down lists of the most popular videos in various content categories, accompanied by an extensive website that offered popularity measures from selected markets around the world. The reception to this approach was mixed as the video generated less mainstream vitriol, but still earned over eight million dislikes within two months of release. YouTube's metricized approach was meant to look both more global and more objective, but the ambiguity and secrecy around how the platform generated these metrics and why it only released them for certain areas of the world shows that it was still a carefully framed corporate operation. Additionally, the sterility of metrics extracted much of the celebratory joy and creativity from Rewind, perhaps in an attempt to simply avoid controversy rather than generate excitement.

Tracing the flows of content creation, including the corporate-produced Rewind videos and critical response and reaction videos from YouTube creators, such as PewDiePie's popular "Rewind 2018, but it's actually good," reveals competing visions for and structuring tensions of platform culture. This constellation of videos helps draw out what danah boyd terms the "networked public" of YouTube, or "the imagined collective that emerges as a result of the intersection of people, technology, and practice" on the platform $(2010,39)$. Former Disney chairman Jeffrey Katzenberg once claimed, "YouTube tells our collective story" (n.d.) - if this is so, who makes up the collective and would they all tell the same story?

Recognizing what makes a social media event and why they generate such engaged attention can point towards other ways of understanding platform cultures. Julia 
Sonnevend defines events as moments that "structure our social lives and give reference points for our life stories and global histories" $(2016,109)$. From viewerdriven virality, to the establishment of microcelebrities, to the role of international cultural leaders like PewDiePie and the Paul brothers across the English-speaking world, Luccas Neto in Brazil, Namewee in Malaysia, Spanish-language channels like elrubiusOMG and Vegetta777, and Arabic YouTubers like EyshElly, understandings of what it means to be a YouTuber emerge from more sectors than ever before. Is a singular Rewind possible for a platform that now encompasses over 100 countries and 80 languages? If corporate visions of what YouTube is and should be no longer generate popular excitement and backing, who then gets to speak for the platform? Focusing on YouTube's premiere cultural event offers a starting point for understanding what YouTube means to those who structure their lives on and around the platform.

\section{References}

boyd, danah. 2010. "Social Network Sites as Networked Publics: Affordances, Dynamics, and Implications." In A Networked Self: Identity, Community, and Culture on Social Network Sites, 47-66. Routledge.

Burgess, Jean, Peta Mitchell, and Felix Münch. 2018. "Social Media Rituals: The Uses of Celebrity Death in Digital Culture." In A Networked Self: Birth, Life, Death, 224-239. Taylor and Francis.

Dayan, Daniel, and Elihu Katz. 1992. Media Events: The Live Broadcasting of History. Harvard UP.

Katzenberg, Jeffrey. No date. Review of Videocracy, by Kevin Allocca, available on Amazon.

Palladino, Valentina. 2019, 4 February. "YouTube is trying to prevent angry mobs from abusing 'dislike' button." arsTechnica.

Sonnevend, Julia. 2016. "Event." In Digital Keywords: A Vocabulary of Information Society and Culture, 109-117. Princeton UP.

Wojcicki, Susan. 2020, 14 February. "YouTube at 15: My personal journey and the road ahead." YouTube Official Blog.

---. 2019, 5 February. "YouTube in 2019: Looking back and moving forward." YouTube Official Blog. 